\title{
A FORMAÇÃO HUMANA NO ENSINO MÉDIO INTEGRADO: o que dizem as pesquisas ${ }^{1}$
}

\author{
Crislaine Cassiano Drago ${ }^{2}$
}

\begin{abstract}
Resumo
Neste trabalho, pretende-se apresentar uma análise sobre as discussões acerca da formação humana no Ensino Médio Integrado (EMI), constantes em artigos, dissertações e teses publicados no Repositório da Coordenação de Aperfeiçoamento de Pessoal de Nível Superior (Capes) entre os anos 2000 e 2015. A partir dos dados coletados, a pesquisa busca traçar um panorama das concepções de formação humana presentes nas publicações que tratam desta forma de oferta de educação básica, evidenciando seus fundamentos teóricos a respeito da formação humana no processo de integração entre ensino médio e educação profissional no Brasil. As conclusões do estudo revelam que o Ensino Médio Integrado é marcado pela dualidade estrutural e que sua materialidade, embasada numa concepção de educação politécnica, ainda não se efetivou na sociedade brasileira. Parte disso se deve às discussões ainda restritas sobre esta temática. Porém, apesar das limitações impostas pelo sistema capitalista, o EMI se constitui como possibilidade de formação emancipatória da classe trabalhadora, contribuindo para o desenvolvimento de sua autonomia e participação cidadã na busca por uma sociedade mais democrática.
\end{abstract}

Palavras-chave: Formação Humana; Ensino Médio Integrado; Educação Profissional.

\begin{abstract}
In this paper, we intend to present an analysis of the discussions about Human Formation in Integrated Higher Education (EMI), contained in articles, dissertations and theses published in the Repository of Coordination for the Improvement of Higher Education Personnel (A.k.a. Capes) between 2000 and 2015. Based on the collected data, the research seeks to outline the conceptions of human formation present in the publications which deal with this form of basic education offer, evidencing its theoretical foundations regarding the human formation in the integration process between high school and professional education in the Brazil. The conclusions of the study show that Integrated Secondary Education is marked by structural duality and that its materiality, based on a conception of polytechnical education, has not become effective in Brazilian society until present days. Part of this is due to the still limited discussions on this subject. However, despite the limitations imposed by the capitalist system, the EMI constitutes a possibility of emancipatory formation of the working class, contributing to the development of its autonomy and citizen participation in the search for a more democratic society.
\end{abstract}

Keywords: Human Formation; Integrated High School; Professional Education.

\footnotetext{
DOI: https://doi.org/10.22409/tn.15i28.p9643

2 Mestranda em Educação Profissional pelo Instituto Federal de Educação, Ciência e Tecnologia do Rio Grande do Norte- PPGEP/IFRN. Pedagoga no Instituto Federal de Educação, Ciência e Tecnologia do Amapá - IFAP/Campus Macapá.
}

TrabalhoNecessario - www.uff.br/trabalhonecessario; Ano 15, №28/2017 


\section{Introdução}

O presente trabalho objetiva apresentar um panorama acerca da concepção de formação humana presente nos estudos sobre o Ensino Médio Integrado (EMI), buscando explicitar os fundamentos teóricos, análises e discussões realizadas pelos autores, bem como os aspectos evidenciados por eles quanto aos limites e avanços da área. A pesquisa realizou-se por meio do levantamento das publicações constantes no Repositório da Coordenação de Aperfeiçoamento de Pessoal de Nível Superior (Capes), publicadas no período de 2000 a 2015, utilizando-se dos descritores Formação Humana; Ensino Médio Integrado e Educação Profissional. A partir da análise das publicações, busca-se traçar um cenário das concepções de formação humana presentes nos estudos acerca da integração entre ensino médio e educação profissional no Brasil.

As análises, discussões e reformulações realizadas sobre o ensino médio durante os últimos anos, especialmente nos anos 2000, revelam a defesa pela construção de uma política de formação que vá além da simples preparação para o ingresso no ensino superior. Como etapa final da educação básica, o ensino médio é uma fase fundamental na formação dos jovens, concluindo sua formação elementar e tornando-os aptos à participação social, política e econômica. Por outro lado, a trajetória histórica das relações entre educação básica e profissional é fortemente marcada por um viés pragmatista, assumindo ainda mais o caráter preparatório, porém com centralidade numa formação voltada para a preparação dos jovens para a ocupação de postos de trabalho, muitas vezes precarizados e mal remunerados.

Para que esta dicotomia seja plenamente superada, faz-se necessária também a superação do modo de produção capitalista, algo muito distante nas relações concretas presentes na sociedade atual. Neste contexto, o que se busca é uma educação capaz de romper com a dicotomia entre trabalho intelectual e trabalho manual, ou seja, um projeto de educação que integre estas duas dimensões na formação dos jovens e dos adultos que chegam ao ensino médio, tendo o trabalho como princípio educativo. Tal formação inclui o mundo do trabalho, mas não tem por obrigação preparar para o desempenho de funções no mercado, mas para a compreensão das correlações de forças e das disputas inerentes ao mundo do trabalho na sociedade capitalista. 
Neste sentido, Saviani (2003, p. 136) entende o ensino médio como uma etapa onde se deve explicitar como o trabalho se desenvolve e se organiza na sociedade moderna. A partir da perspectiva da politecnia, todo trabalho humano envolve aspectos manuais e intelectuais, e sua dissociação é uma construção social e histórica. Desta forma, para Moura (2013b, p. 146), buscase a construção de um EMI politécnico, unitário e universal, que tenha por objetivo a superação da dualidade que marca a educação brasileira e a construção de uma sociedade em que os jovens possam optar por uma profissão apenas quando concluírem o ensino médio.

O que se pretende, pois, é a construção de uma educação fundamentada na concepção de formação humana integral, uma educação capaz de integrar os aspectos inerentes ao mundo do trabalho, aliados a uma sólida formação crítica, autônoma e cidadã. Para que se possam vislumbrar formas de se alcançar este objetivo, é fundamental a construção de uma compreensão aprofundada destes conceitos, a fim de se avançar no delineamento de práticas capazes de instituir o tipo de formação de nível médio que se almeja materializar.

\section{Metodologia}

O estudo foi construído por meio de pesquisa realizada no Repositório Capes no segundo semestre de 2016 a partir de descritores relacionados à temática citada, apresentando poucas variações de resultados encontrados no período em questão. O recorte temporal adotado para a pesquisa foi o período de 2000 a 2015. Pretendeu-se com este recorte a seleção e análise de trabalhos publicados no contexto das transformações sociais, econômicas e políticas em curso nos anos 2000, procurando identificar possíveis referências deste contexto nas produções dos pesquisadores. Os descritores utilizados nas buscas relacionavam-se com as concepções de formação contidas no título ou no interior dos trabalhos, com o objetivo de identificar qual a abordagem dos autores sobre estas concepções.

É importante ressaltar que os termos utilizados foram pesquisados utilizando-se aspas, visto que ao se realizar a pesquisa sem a utilização deste recurso foi encontrada uma multiplicidade de trabalhos que pouco se relacionavam com o foco pretendido. Como exemplo, ao buscar o termo

TrabalhoNecessario - www.uff.br/trabalhonecessario; Ano 15, №28/2017 
Formação Humana, sem aspas, encontramos 3.676 trabalhos e quando se buscou o mesmo termo entre aspas, encontramos apenas 292 ocorrências, nas quais os trabalhos realizavam discussões acerca do EMI, temática explorada nesta pesquisa.

Neste sentido, num primeiro momento, os termos buscados foram: Educação Profissional (714); Formação Humana (292) e Ensino Médio Integrado (41), totalizando 1.047 trabalhos. Muitos destes textos referiam-se à formação de professores para a educação básica e superior e, ainda, a formação de profissionais para outras áreas de atuação, fora do âmbito de interesse deste estudo. Entre estas áreas com maior ocorrência de abordagem destacam-se as de saúde e nutrição (enfermagem, medicina, vigilância sanitária), contabilidade e administração. Assim, por não estarem diretamente relacionadas ao escopo pretendido, estas publicações foram desconsideradas. Foram ainda pesquisados novos descritores relacionados à concepção de formação humana integral. Nesta etapa, obteve-se o seguinte resultado: Escola Unitária (16); Politecnia (32) e Omnilateralidade (05).

Considerando a quantidade de resultados obtidos demasiado abrangente para os limites e objetivos da análise que se pretendia realizar, procedeu-se à etapa de seleção dos trabalhos. Os critérios utilizados para a triagem foram: 1) os estudos que se relacionavam de forma mais direta com as concepções de formação humana no EMI; 2) pesquisas cujo enfoque do ensino médio situavam-se a partir da perspectiva da formação humana integral, com base na politecnia e 3) estudos delimitados apenas ao Brasil e realizados no período delimitado (2000-2015).

Após a seleção segundo os critérios descritos e compreendendo que as buscas realizadas continham um número suficiente de elementos para a realização da análise desejada, as pesquisas selecionadas foram então reagrupadas, excluindo-se os trabalhos em duplicidade, sendo por fim escolhidas 11 (onze) publicações, das quais 5 (cinco) eram artigos e 2 (dois) ensaios, publicados em revistas científicas ou periódicos; 2 (duas) dissertações de Mestrado (UnB e UFRGS) e 2 (duas) teses de Doutorado (USP e Unicamp), todos desenvolvidos em programas na área da Educação, situados nas regiões centro-oeste, sul e sudeste. Não foram encontradas entre as dissertações e teses selecionadas nenhuma realizada nas regiões norte e nordeste do país. 
Após esta análise preliminar, as pesquisas foram organizadas de acordo com nome dos autores e ano de publicação, tipo de trabalho e objetivos, conforme apresentado no quadro 1 (um), ao final deste trabalho.

O enfoque nos objetivos dos trabalhos se deu devido à necessidade de se ter uma visão mais ampla em relação ao seu conteúdo e ao objeto delimitado por cada autor. Para tanto, buscou-se localizar os objetivos nos resumos das publicações, a fim de que fosse possível constatar quais as suas relações com as concepções de formação humana que se anunciavam de forma explícita, ou buscar desvelar as concepções que poderiam estar implícitas nos objetivos elencados pelos autores.

Optou-se por utilizar a ordem de apresentação dos autores pelo conteúdo das temáticas abordadas por eles. Por este motivo, os trabalhos não são apresentados em ordem cronológica nem os autores em ordem alfabética. Tal opção se justifica pela construção do encadeamento lógico das ideias e discussões no corpo do texto. Apresentamos em seguida as concepções de formação humana no Ensino Médio Integrado presentes nas publicações analisadas, bem como o posicionamento dos autores acerca dos principais conceitos abordados no que se refere à educação integral.

\section{3. $\mathrm{O}$ que dizem as pesquisas}

Os trabalhos selecionados sinalizam, desde os seus resumos, as concepções dos autores a respeito do tipo de formação humana a ser adotada no processo de escolarização dos jovens estudantes do ensino médio integrado à educação profissional. De modo geral, os autores procuram contextualizar historicamente o processo de constituição da educação profissional no Brasil e suas relações com a educação básica, enfatizando avanços, limites e perspectivas para a sua integração.

Defendem um ensino médio que caminhe em direção à formação humana integral, sendo esta compreendida a partir do referencial teórico materialista histórico-dialético, tendo como base a concepção de formação integrada e o princípio da politecnia. Os estudos têm em comum, ainda, o objetivo de desejarem contribuir para a construção da autonomia e emancipação dos jovens da classe trabalhadora como forma de estruturar as bases de uma nova sociedade, mais justa e igualitária. 
Situando a origem histórica das concepções de formação integrada e de politecnia a partir do materialismo histórico, Ferretti (2009) ressalta que estas concepções não são exclusivas deste campo teórico, sendo encontradas em outros aportes teóricos com significados distintos. Tal fato demonstra que a polissemia que envolve os termos formação integrada e politecnia pode conduzir a interpretações diversas e muitas vezes antagônicas. Busca evidenciar a forma como Marx/Engels e Gramsci elaboram suas visões sobre as relações entre educação e trabalho mediadas pelas concepções de politecnia e formação integrada, bem como as aproximações e distanciamentos entre eles.

Aponta que as obras de Marx e Engels e Gramsci abordam a educação numa perspectiva histórico-política, focada no conflito entre as classes na sociedade capitalista. Afirma que Marx/Engels defendiam a união entre 0 ensino e o trabalho produtivo por meio da combinação entre ensino intelectual, exercícios físicos e formação politécnica. Esta articulação se constituiria como elemento central da formação da classe trabalhadora, contribuindo para o desenvolvimento superior do homem. Neste sentido, é central em Marx a perspectiva de que o ensino politécnico fundamenta-se na relação teoria e prática (FERRETTI, 2009).

Gramsci, por sua vez, via a escola tanto como elemento de reiteração do poder das classes dominantes quanto local de realização da reforma intelectual das massas, com vistas à superação da sociedade capitalista. Neste sentido, entende como ideal educativo a ser buscado é uma educação unitária, ou seja, uma educação inicial de caráter humanista e de cultura geral em seu caráter mais amplo (ensino primário), seguida de crescente orientação profissional (ensino secundário), fundamentada nos princípios humanistas de autodisciplina intelectual e autonomia moral, necessárias à futura profissionalização (FERRETTI, Op. Cit.).

Com isso, Ferretti identifica como semelhanças entre Marx/Engels e Gramsci o materialismo dialético como perspectiva teórica e a preocupação política com a superação da sociedade capitalista, sendo a educação escolar a possibilidade concreta de desenvolvimento dos trabalhadores. Por outro lado, as diferenças estão situadas no contexto histórico específico em que viviam, visto que Marx/Engels admitem aliar educação e trabalho no processo de 
formação das crianças operárias no século XIX, enquanto Gramsci busca integrar educação e trabalho de forma diversa, de acordo com o momento vivido por ele no início do século XX.

A noção de politecnia é apresentada e problematizada no texto de Saviani (2003), o qual postula que o processo de trabalho deve desenvolver os aspectos materiais e intelectuais de forma indissolúvel. Acerca do conceito de politecnia, afirma que esta deriva da problemática do trabalho, pois, "toda a educação organizada se dá a partir do conceito e do fato do trabalho, portanto, do entendimento e da realidade do trabalho" (SAVIANI, 2003, p. 132).

Assim, a politecnia se refere ao domínio dos fundamentos científicos das diversas técnicas que caracterizam o processo produtivo, o domínio dos princípios científicos que fundamentam o trabalho (SAVIANI, 2003). Acrescenta que a politecnia caminha na direção da superação da dicotomia entre trabalho manual e intelectual, formação geral e profissional, concebendo a educação como um processo inteiro que envolve e integra as diversas dimensões da vida humana sem hierarquizá-las.

Abordando o processo histórico de construção do modelo de ensino médio vigente no país a fim de situar a educação profissional voltada para a área da saúde, o ensaio escrito por Wermelinger; Machado e Amâncio Filho (2007, p. 207) discute, a partir de análise sobre a legislação brasileira, a dualidade presente no ensino médio, a associação entre discriminação social e ocupações técnicas e a contenção da demanda pelo acesso ao ensino superior no país. Para os autores, o processo de integração entre ensino médio e profissional, instituído de forma compulsória na década de 1970, apresentou múltiplas dificuldades. Entre elas, destacam:

[...] o viés acadêmico de que se revestiu a proposta, a falta de esclarecimento dos professores em relação ao projeto, a falta de incentivo para adoção e aplicação das novas diretrizes e a carência de professores qualificados para ministrarem disciplinas novas (OLIVEIRA, 1981, p.133-134). Pode-se acrescentar a esses fatores a falta de apoio ao modelo por parte da sociedade, que continuava a compreender o ensino secundário como uma etapa preparatória para a universidade [...]. (WERMELINGER; MACHADO; AMÂNCIO FILHO. 2007, p. 210). 
Desta forma, o projeto de formação profissional compulsória no ensino médio não obteve apoio por parte das classes mais abastadas que matriculavam seus filhos na rede privada ensino, visto que esta não cumpriu 0 estabelecido em Lei. Tal fato aprofundou ainda mais a dualidade: escola profissional de nível médio para os pobres e propedêutica para os que poderiam continuar seus estudos em nível superior. Como alternativa para a superação deste impasse, apontam uma educação profissional de nível médio tendo por base o trabalho como princípio educativo.

Argumentam que a formação de nível médio deve ser fundamentada em uma visão crítica do contexto social, articulando o domínio da técnica com a ação política. Neste sentido, apontam a politecnia como uma alternativa à formação profissional técnica de nível médio na área da saúde com o intuito de afastá-la do modelo de educação profissional com caráter de terminalidade, pois, consideram que "a educação politécnica permitiria propiciar ao trabalhador a formação centrada no desenvolvimento multidimensional, capaz de habilitá-lo para o exercício de diversificadas funções, rejeitando adestramentos direcionados para tarefas específicas" (WERMELINGER; MACHADO; AMÂNCIO FILHO. 2007, p. 211).

Com o objetivo de realizar uma síntese histórica da relação entre a educação profissional (EP) e a educação básica (EB) no ensino médio, o artigo escrito por Moura (2010) busca analisar esta relação no contexto dos anos 2000 e suas perspectivas no Plano Nacional de Educação (PNE) então em processo de elaboração. Para tanto, analisa a produção acadêmica da área e os documentos oficiais, em especial o Documento Final da Conferência Nacional de Educação (CONAE) realizada em 2010.

A integração entre educação básica e profissional, dissolvida na década de 1990 por meio do Decreto no 2.208/1997, é retomada no âmbito da legislação nos anos 2000, a partir da promulgação do Decreto $n^{\circ} 5.154 / 2004$, que aponta novamente sua possibilidade de integração, mesmo mantendo elementos de articulação presentes no Decreto anterior (nas formas oferta subsequente e concomitante). Desta forma, o EMI se apresenta como uma possibilidade de avanço na construção de um ensino médio igualitário. Fundamentado no princípio da politecnia, se constitui na travessia para uma nova realidade, na qual os jovens das classes populares possam, assim como 
os das classes mais abastadas, ter acesso à continuidade dos estudos e à possibilidade de escolha de uma profissão apenas após a conclusão da educação básica, sendo uma forma de se romper com a dualidade estrutural que marca a educação brasileira.

Em outro texto, Moura (2013a, p.705) confirma a perspectiva do EMI como uma possibilidade de se avançar na direção de uma educação que proporcione aos jovens da classe trabalhadora uma "formação omnilateral, integral ou politécnica de todos, de forma pública e igualitária e sob a responsabilidade do estado", questionando se é possível que se caminhe nesta direção na atual sociedade brasileira, periférica e marcada pelo sistema capitalista. Tomando como referência os escritos de Karl Marx, Friedrich Engels e Gramsci, ratifica o EMI como a possível "travessia" entre a educação atual e a pretendida para a emancipação da classe trabalhadora, concluindo que o ensino médio deve garantir uma base unitária para todos, fundamentada na concepção de formação humana integral e tendo como eixos o trabalho, a ciência, a tecnologia e a cultura.

Numa perspectiva aproximada, o ensaio de Rodrigues (2005) objetiva analisar os efeitos do Decreto no 5.154/2004, que reestrutura as formas de oferta da educação profissional, e os limites impostos à educação pelo modo de produção capitalista, manifestados pela dualidade estrutural da escola. Diante deste contexto, retoma a concepção de educação politécnica "como um (ainda) novo horizonte de debate teórico, político e pedagógico para o campo da educação profissional" (2005, p.259).

Aponta o texto intitulado "Sobre a concepção de Politecnia", apresentado por Saviani no Seminário Choque Teórico em 1987, como um marco referencial nas discussões da área de trabalho e educação, principalmente para as discussões sobre as relações entre ensino médio e técnico como uma forma de superação da dualidade educacional brasileira. No entanto, apesar da repercussão deste marco, afirma que o debate entre ensino médio e técnico na perspectiva da politecnia ficou restrita a poucos interessados, mesmo após os efeitos do Decreto no 2.208/1997, já comentados anteriormente, entrando novamente no cenário educacional a partir da promulgação do Decreto $\mathrm{n}^{\circ}$ $5.154 / 2004$. 
Estão no cerne destes debates posições contrárias nas quais um grupo entende ser este o caminho possível para a superação da dualidade entre educação profissional e ensino médio e, por outro lado, outro grupo considera ser este uma forma de naturalizar esta dualidade. A fim de superar esse impasse, Rodrigues propõe a retomada urgente do debate e a defesa da educação politécnica, assim como a luta contra o avanço do capital sobre o trabalho e contra uma educação fragmentada e voltada para a empregabilidade. Considera, enfim, que defender a politecnia é ir na contramão do avanço neoliberal e favor de uma educação omnilateral para a classe trabalhadora.

Considerando o trabalho pedagógico como uma das formas históricas mais significativas de disciplinamento para a vida social e produtiva, no contexto das relações capitalistas de produção, Ignacio (2009) busca compreender de que forma o atual modo de produção capitalista, marcado pela acumulação flexível, abre espaço para que a concepção de educação politécnica ingresse na discussão das políticas educacionais brasileiras. Para o autor, a "desespecialização dos trabalhadores - e sua transformação em operários polivalentes - passa a ser uma demanda concreta do novo padrão de acumulação" (IGNACIO, 2009, p. 193), demanda esta que passa a nortear as políticas educacionais brasileiras.

Conclui que as contradições presentes no sistema capitalista produzem brutais desigualdades ainda mais exacerbadas no modelo de acumulação flexível. Postula uma educação profissional voltada à classe trabalhadora, que vá além da simples formação de mão de obra para atender aos interesses do modo de produção capitalista mas, sim, uma educação que permita-Ihes compreender sua condição histórica e social e contribuir de forma ativa na construção de uma nova sociabilidade, mais justa e igualitária.

Buscando compreender como essas concepções são materializadas no cotidiano das escolas técnicas de nível médio, apresenta-se o estudo de Bezerra (2012) que, em sua dissertação de Mestrado, analisa as matrizes curriculares e os planos de ensino dos professores de Língua Estrangeirainglês dos cursos técnicos de nível médio dos Institutos Federais, considera que as bases filosóficas, epistemológicas e pedagógicas do EMI são oriundas da concepção de educação omnilateral e politécnica de Marx e Engels, da 
escola unitária de Gramsci e do currículo integrado. Por outro lado, alega que os Institutos Federais (IF), têm por missão "escamotear a dualidade de classes brasileira via superação da dualidade histórica entre formação geral e formação profissional" (2012, p. 7).

$A$ análise de Bezerra, neste e em outro texto escrito em conjunto com seu orientador (BEZERRA; JOVANOVIC, 2015), evidencia que, apesar dos discursos presentes nos documentos institucionais seguirem na direção da formação humana integral, sua adoção ou não fica a cargo das instituições. Para os autores, a concepção de formação integral não é incorporada pelos planos curriculares e de ensino das instituições e seus professores. Os referidos autores concluem que o papel de adesão das instituições no aprofundamento dos construtos do EMI é fundamental para a sua materialização no âmbito escolar, com vistas a romper a dualidade histórica presente no sistema educacional brasileiro.

Ao analisar a percepção dos docentes do curso técnico em Turismo do Instituto Federal do Pará - IFPA - Campus Belém, acerca da concepção de formação integral na prática docente, Figliuolo (2010, p. 8) aborda o EMI e a politecnia nos embates travados desde o seu início e apresenta, ainda, um breve histórico dos impactos, na Educação Profissional e no contexto mundial, dos organismos internacionais e sua relação com as Políticas Públicas para a Educação Profissional no Brasil.

Figliuolo (2010) busca analisar as percepções dos docentes acerca de como está se dando, na prática, a integração entre ensino médio e educação profissional e o significado do Ensino Médio Integrado, procurando detectar os avanços e retrocessos dessa implementação. Conclui que é necessário investimento da instituição na formação continuada de professores, tanto das disciplinas gerais quanto das específicas do curso técnico em Turismo (2010).

Tendo por objeto a relação trabalho-escola, Pergher (2012, p. 8), a partir da experiência desenvolvida no Instituto de Educação Josué de Castro, buscando analisar de que forma esta experiência demonstra o aporte teóricoprático da Pedagogia Socialista da classe trabalhadora na direção de seu projeto histórico, a partir da prática desenvolvida pelos educandos na escola. Discute a relação trabalho-escola tendo o trabalho como princípio educativo e 
ensaia elementos da perspectiva politécnica na escola à luz da Pedagogia Socialista.

Pergher (2012) reafirma a "necessidade de uma alternativa radical a este modo de produzir a vida gerida e pautada pelo capital, que só pode ser fruto da luta dos trabalhadores, a necessidade do socialismo" (PERGHER, 2012, p. 144). Conclui que a relação trabalho-escola traz em seu bojo elementos de contraposição à lógica do capital e proporciona experiências alternativas nas relações de trabalho aos estudantes. Tal fato é destacado por ele como um ponto relevante na formação dos estudantes, contribuindo assim para o projeto educativo da classe trabalhadora, com base na Pedagogia Socialista e em elementos na perspectiva da politecnia.

O conjunto dos trabalhos analisados revela aspectos fundamentais para a compreensão das discussões atuais sobre o EMI e como uma educação de nível médio, de base politécnica, pode se fazer presente nas políticas educacionais do país, no contexto das relações capitalistas de produção. Além disso, esses estudos conduzem a reflexões importantes sobre como esta educação, a partir da perspectiva da formação humana integral, pode ser materializada nas escolas brasileiras.

Os estudos revelam que as práticas docentes e institucionais ainda não adotaram plenamente o EMI como uma possibilidade de formação inteira para os jovens da classe trabalhadora. Mesmo sendo esta uma discussão bastante difundida no meio acadêmico, como revela o número significativo de trabalhos encontrados, muitos aspectos ainda não foram discutidos ou abordados, causando uma lacuna que dificulta a compreensão profunda da concepção de formação humana integral e sua disseminação nos círculos que atuam diretamente com o EMI.

Somam-se a essas discussões os acontecimentos recentes da política educacional brasileira, no qual se introduz um novo conjunto de reformulações que distanciam ainda mais educação básica e profissional numa perspectiva politécnica e emancipadora. Apresentando uma consistente retomada da trajetória histórica das reformulações do ensino médio, Ferretti (2016) evidencia que estas se resumem basicamente a alterações na estrutura e conteúdo do currículo. Quanto à educação profissional, enfatiza que suas Diretrizes Curriculares são "marcadas pelo hibridismo entre a concepção político- 
educacional pautada pela formação politécnica e omnilateral e a fundamentada na formação por competência" (FERRETTI, 2016, p. 85).

A reforma do ensino médio que se realiza atualmente de forma bastante controversa pelo atual governo, instituída por meio do Projeto de Lei de Conversão (PLV) 34/2016, de 8 de fevereiro de 2017, mais uma vez modifica apenas o currículo deste nível de ensino. Sob o discurso de flexibilização e maior liberdade e autonomia para os estudantes do ensino médio, a atual reforma deixa claro que os projetos societários em disputa estão pendendo cada vez mais para o viés pragmatista, promovendo o esvaziamento deste nível de ensino. Neste contexto, a materialização da integração entre educação básica e profissional numa perspectiva politécnica se torna ainda mais distante.

\section{Considerações finais}

À luz das análises realizadas pelos autores das publicações selecionadas, tem-se um panorama acerca das pesquisas sobre a formação humana no Ensino Médio Integrado. Estas análises são fundamentadas no materialismo histórico dialético, notadamente a partir das obras de Karl Marx, Friedrich Engels e Antônio Gramsci. A integração entre ensino médio e educação profissional, fundamentada na concepção de formação integral e no princípio da politecnia, é apresentada como uma possibilidade de superação da dualidade que marca a educação brasileira.

A proposta de uma educação de base politécnica para os jovens da classe trabalhadora por meio do EMI é então problematizada e discutida como o caminho a ser trilhado na busca da emancipação da classe trabalhadora e para a construção de uma cidadania participativa. No entanto, o atual estágio da sociedade brasileira, marcada pelo sistema capitalista, limita a realização deste projeto, reforçando a dualidade educacional como forma de sustentação de seu sistema político-econômico.

As pesquisas que abordam as percepções e práticas dos docentes sobre a concepção de politecnia, bem como dos currículos e políticas de gestão das instituições, demonstram que a materialização de uma formação humana integral, que tenha como fundamento o trabalho, a ciência, a tecnologia e a cultura, é algo possível, porém ainda distante da realidade do sistema educacional brasileiro. $O$ investimento na formação continuada dos

TrabalhoNecessario - www.uff.br/trabalhonecessario; Ano 15, №28/2017 
docentes é, assim, proposto como um caminho para a superação destas limitações.

Diante das discussões propostas nos estudos analisados, entendemos que a temática da formação humana necessita ser ainda aprofundada, suscitando a necessidade de realização de novos estudos que avancem na direção da superação das limitações encontradas pelos autores. As discussões acerca da temática proposta neste trabalho devem, também, contribuir para a compreensão da concepção de politecnia como embasamento teórico a partir do qual se possam construir propostas educacionais capazes de materializar, de forma efetiva, a formação da classe trabalhadora na perspectiva de sua emancipação.

Por fim, as conclusões deste estudo revelam que o Ensino Médio Integrado é marcado pela dualidade estrutural e que sua materialidade, embasada numa concepção de educação politécnica, ainda não se efetivou na sociedade brasileira. Parte disso se deve às discussões ainda restritas sobre esta temática. Porém, apesar das limitações impostas pelo sistema capitalista, - EMI se constitui como possibilidade de formação emancipatória da classe trabalhadora, contribuindo para o desenvolvimento de sua autonomia e participação cidadã na busca por uma sociedade mais democrática. 


\section{Referências Bibliográficas}

BEZERRA, D. de S. Políticas e planejamento do ensino médio (integrado ao técnico) e da língua estrangeira (inglês): na mira(gem) da politecnia e da integração. 2012. Tese (Doutorado em Educação) - Faculdade de Educação, Universidade de São Paulo, São Paulo, 2012. Disponível em: http://www.teses.usp.br/teses/disponiveis/48/48134/tde-05022013-105725/.

Acesso: de 7 a 14 jul. 2016.

BEZERRA, D. de S.; JOVANOVIC, A. Trabalho, formação integral e ensino de língua estrangeira: (des) encontros no Ensino Médio integrado ao Técnico. Conjectura: Filos. Educ., Caxias do Sul, v. 20, n. 1, p. 101-118, jan./abr. 2015. Disponível em: http://www.ucs.br/etc/revistas/index.php/conjectura/article/viewArticle/2577. Acesso: 22 fev. 2017.

COORDENAÇÃO DE APERFEIÇOAMENTO DE PESSOAL DE NIVEL SUPERIOR - CAPES. Ministério da Educação. Portal de Periódicos. Disponível em: http://www.periodicos.capes.gov.br/. Acesso: de 7 a 14 jul. 2016.

FERRETTI, C. J. O pensamento educacional em Marx e Gramsci e a concepção de politecnia. Trab. educ. saúde, Rio de Janeiro, v. 7, supl. 1, p. 105-128, 2009.2 Disponível em: http://www.scielo.br/scielo.php?script=sci arttext\&pid=S198177462009000400006\&lng=en\&nrm=iso. Acesso: de 7 a 14 jul. 2016.

FERRETTI, C. J. Reformulações do Ensino Médio. HOLOS, [S.I.], v. 6, p. 71 91, out. 2016. ISSN 1807-1600. Disponível em: http://www2.ifrn.edu.br/ojs/index.php/HOLOS/article/view/4988/1570. Acesso em: 22 fev. 2017.

FIGLIUOLO, A. C. do L. Ensino Médio Integrado: um estudo de caso sobre a percepção docente acerca da implementação do Decreto no 5.154/04 no curso de turismo do Instituto Federal de Educação, Ciência e Tecnologia do Pará Campus Belém. 2011. Dissertação (Mestrado em Educação). - Faculdade de Educação, Universidade de Brasília, Brasília, 2010.

FRIGOTTO, G. Concepções e mudanças no mundo do trabalho e o ensino médio. In: FRIGOTTO, G.; CIAVATTA, M.; RAMOS M. (orgs.) Ensino Médio 
Integrado: Concepções e contradições. 3ª ed. São Paulo: Cortez, 2012.

IGNACIO, P. C. de S. Capitalismo, acumulação flexível e educação profissional no Brasil: polivalência ou politécnica? 2009. Tese (Doutorado em Educação) - Faculdade de Educação, Universidade Estadual de Campinas, Campinas, São Paulo, 2009. Disponível em: http://www.bibliotecadigital.unicamp.br/document/?code=000469671. Acesso: de 7 a 14 jul. 2016.

MOURA, D. A Relação entre a educação profissional e a educação básica na CONAE 2010: possibilidades e limites para a construção do novo Plano Nacional de Educação. Educ. Soc., Campinas, v. 31, n. 112, p. 875-894, Set. 2010. Disponível em: http://www.scielo.br/pdf/es/v31n112/12.pdf. Acesso: de 7 a 14 jul. 2016.

MOURA, D. H. Ensino médio integrado: subsunção aos interesses do capital ou travessia para a formação humana integral? Revista Educação \& Pesquisa, São Paulo, v. 39, n. 3, p. 705-720, jul./set. 2013a.

MOURA, D. H. Ensino Médio e Educação Profissional no Brasil nos anos 2000: Movimentos contraditórios. In: MOURA, D. H. (org.) Produção do Conhecimento, Políticas Públicas e Formação Docente em Educação Profissional. Campinas, São Paulo: Mercado das Letras, 2013b.

PERGHER, E. G. A escola do trabalho: um estudo no Instituto de Educação Josué de Castro. 2012. Dissertação (Mestrado em Educação). - Faculdade de Educação, Universidade Federal do Rio Grande do Sul, Porto Alegre, Rio Grande do Sul, 2012. Disponível em: http://hdl.handle.net/10183/61749. Acesso: de 7 a 14 jul. 2016.

RODRIGUES, J. Ainda a educação politécnica: o novo decreto da educação profissional e a permanência da dualidade estrutural. Trab. educ. saúde, Rio de Janeiro, v. 3, n. 2, p. 259-282, Set. $2005 . \quad$ Disponível em: http://www.scielo.br/scielo.php?script=sci arttext\&pid=S198177462005000200002\&lng=en\&nrm=iso. Acesso: de 7 a 14 jul. 2016.

SAVIANI, D. O choque teórico da Politecnia. Trabalho, Educação e Saúde, Rio de Janeiro, v. 1, n. 1, p. 131-152, mar. 2003. Disponível em: http://www.scielo.br/scielo.php?script=sci arttext\&pid=S1981$\underline{77462003000100010 \& \operatorname{lng}=\text { pt\&nrm=iso. }}$. Acesso: jul. 2016.

WERMELINGER. M.; MACHADO, M. H.; AMÂNCIO FILHO, A. Políticas de educação profissional: referências e perspectivas. Ensaio: aval. pol. públ. Educ., Rio de Janeiro, v.15, n.55, p. 207-222, abr.jun. 2007. Disponível em: http://www.scielo.br/pdf/ensaio/v15n55/a03v1555.pdf. Acesso: de 7 a 14 jul. 2016. 
Quadro 1 - Trabalhos selecionados para a análise.

\begin{tabular}{|c|c|c|c|}
\hline № & AUTORES & $\begin{array}{l}\text { TIPO DE } \\
\text { TRABALHO }\end{array}$ & OBJETIVOS \\
\hline 01 & BEZERRA (2012) & $\begin{array}{c}\text { Tese de } \\
\text { Doutorado - } \\
\text { Educação } \\
\text { (USP) }\end{array}$ & $\begin{array}{l}\text { Objetiva entender como a especificidade da forma } \\
\text { integrada de ensino médio com a educação } \\
\text { profissional deveria ser equacionada pelas } \\
\text { instituições (Institutos Federais). }\end{array}$ \\
\hline 02 & $\begin{array}{l}\text { BEZERRA; } \\
\text { JOVANOVIC } \\
\text { (2015) }\end{array}$ & Artigo & $\begin{array}{l}\text { Recorre à história, aos construtos teóricos e às } \\
\text { políticas curriculares para apreender como o que é } \\
\text { historicizado, almejado e prescrito (deveria) } \\
\text { impacta(r) a materialização desse conjunto na } \\
\text { elaboração da dimensão do planejamento de } \\
\text { ensino de Inglês no Ensino Médio Integrado. }\end{array}$ \\
\hline 03 & FERRETTI (2009) & Artigo & $\begin{array}{l}\text { Pretende, de um lado, situar ambas as concepções } \\
\text { no universo teórico do materialismo histórico, } \\
\text { ressalvando que, por não serem exclusivas deste } \\
\text { universo, comparecem em outros, com diferentes } \\
\text { significados. De outro lado, intenciona examinar, } \\
\text { com algum detalhe, de que forma dois autores- } \\
\text { chave - Marx e Gramsci - elaboram suas visões } \\
\text { sobre as relações entre a educação e o trabalho } \\
\text { mediadas pela concepção da politecnia e da } \\
\text { formação integral e, de forma bastante breve, quais } \\
\text { as aproximações e distanciamentos entre eles, } \\
\text { relativamente a tal questão. }\end{array}$ \\
\hline 04 & $\begin{array}{l}\text { FIGLIUOLO } \\
(2010)\end{array}$ & $\begin{array}{l}\text { Dissertação } \\
\text { de Mestrado } \\
\text { em } \\
\text { Educação } \\
\text { (UnB) }\end{array}$ & $\begin{array}{l}\text { O estudo tem por finalidade analisar a percepção } \\
\text { dos docentes que atuam no Curso de Turismo do } \\
\text { Instituto Federal do Pará, Campus Belém, em } \\
\text { relação aos pressupostos da concepção de } \\
\text { formação integral na prática docente. }\end{array}$ \\
\hline 05 & IGNACIO (2009) & $\begin{array}{l}\text { Tese de } \\
\text { Doutorado - } \\
\text { Educação } \\
\text { (Unicamp) }\end{array}$ & $\begin{array}{l}\text { Investiga em que grau, o nível alcançado pela base } \\
\text { técnica da produção na atualidade, marcado pelo } \\
\text { regime de acumulação flexível, dá as condições } \\
\text { objetivas para que o a concepção politécnica de } \\
\text { educação ingresse, definitivamente, no debate } \\
\text { sobre políticas educacionais, ainda que seja no } \\
\text { campo do contraditório e das lutas contra- } \\
\text { hegemônicas, na medida em que, pelas relações } \\
\text { sociais de produção capitalista, o limite é a } \\
\text { polivalência. }\end{array}$ \\
\hline 06 & MOURA (2013a) & Artigo & $\begin{array}{l}\text { Discute o ensino médio integrado à educação } \\
\text { profissional técnica de nível médio como uma } \\
\text { possibilidade de travessia na direção formativa } \\
\text { pretendida para os jovens brasileiros. }\end{array}$ \\
\hline 07 & MOURA (2010) & Artigo & $\begin{array}{l}\text { Discute a relação entre a educação profissional } \\
\text { (EP) e a educação básica (EB), especialmente o } \\
\text { ensino médio (EM), assumindo como pressuposto a } \\
\text { educação como direito igualitário de todos, tendo } \\
\text { em vista a elaboração do novo Plano Nacional de } \\
\text { Educação (PNE) a partir da Conferência Nacional } \\
\text { de Educação (CONAE 2010). }\end{array}$ \\
\hline 08 & PERGHER (2012) & $\begin{array}{l}\text { Dissertação } \\
\text { de Mestrado } \\
\text { em } \\
\text { Educação } \\
\text { (UFRGS) }\end{array}$ & $\begin{array}{l}\text { A pesquisa se desenvolve em torno } \text { da } \\
\text { problemática expressa nas seguintes questões: De } \\
\text { que forma se dá a relação trabalho-escola no } \\
\text { Instituto? Que potencialidades podem ser } \\
\text { destacadas na participação dos educandos no } \\
\text { processo de trabalho no Instituto a partir de } \\
\text { elementos teóricos e práticos? Em que medidaa }\end{array}$ \\
\hline
\end{tabular}




\begin{tabular}{|c|c|c|c|}
\hline & & & $\begin{array}{l}\text { relação trabalho escola que acontece no IEJC } \\
\text { expressa o acúmulo teórico-prático da Pedagogia } \\
\text { Socialista da classe trabalhadora na direção do } \\
\text { projeto histórico? }\end{array}$ \\
\hline 09 & $\begin{array}{l}\text { RODRIGUES } \\
(2005)\end{array}$ & Ensaio & $\begin{array}{l}\text { Analisa o recente decreto sobre educação } \\
\text { profissional, no } 5.154 / 04 \text {, considerando os limites } \\
\text { estruturais impostos pelo modo de produção } \\
\text { capitalista à educação, que se manifestam no } \\
\text { fenômeno da dualidade estrutural escolar. A partir } \\
\text { daí, retoma a concepção de educação politécnica, } \\
\text { como um (ainda) novo horizonte de debate teórico, } \\
\text { político e pedagógico para o campo da educação } \\
\text { profissional. }\end{array}$ \\
\hline 10 & SAVIANI (2003) & Artigo & $\begin{array}{l}\text { O trabalho se originou do Seminário Choque } \\
\text { Teórico, realizado em } 1987 \text { e organizado pela } \\
\text { Escola Politécnica de Saúde Joaquim Venâncio. } \\
\text { Convidado a participar desse seminário para tratar } \\
\text { da concepção de politecnia, o autor fez uma } \\
\text { exposição oral, posteriormente publicada em livro } \\
\text { (Saviani, 1989). A parte I deste artigo é constituída } \\
\text { pela versão revista da exposição apresentada no } \\
\text { referido seminário. A parte II retoma a discussão do } \\
\text { conceito de politecnia, trazendo novos elementos } \\
\text { para a compreensão de seu significado, em } \\
\text { correlação com a situação histórica atual. }\end{array}$ \\
\hline 11 & $\begin{array}{l}\text { WERMELINGER; } \\
\text { MACHADO; } \\
\text { AMÂNCIO FILHO } \\
\text { (2007) }\end{array}$ & Ensaio & $\begin{array}{l}\text { Revisita o processo histórico de construção do } \\
\text { modelo de educação profissional de nível médio } \\
\text { vigente no Brasil, procurando identificar aspectos } \\
\text { que auxiliem na compreensão de questões } \\
\text { pertinentes a essa modalidade de ensino. Aborda a } \\
\text { dualidade do ensino médio, a associação entre } \\
\text { discriminação social e ocupações técnicas, a } \\
\text { contenção de demanda ao nível superior de ensino, } \\
\text { a formação integral do cidadão e a formação para o } \\
\text { mundo do trabalho, situando a educação } \\
\text { profissional na área da saúde nesse contexto. }\end{array}$ \\
\hline
\end{tabular}

Fonte: Repositório CAPES (2016)/Elaboração própria.

Recebido em: 30 de outubro de 2017. Aprovado em: 28 de novembro de 2017.

Publicado em: 31 de janeiro de 2018. 